\title{
THE DETERMINATION OF BLOOD GLUTATHIONE BY AMPEROMETRIC TITRATION
}

\author{
BY \\ D. S. BIDMEAD AND D. WATSON \\ From the South-west and Oxford Regions Rheumatism Research Unit, Royal National \\ Hospital for Rheumatic Diseases, Bath
}

(RECEIVED FOR PUBLICATION SEPTEMBER 5, 1951)

In 1946 Kolthoff and Harris devised a method of titrating mercaptans in aqueous alcoholic solution with silver nitrate. They used a rotating platinum electrode with suitable current measuring equipment to locate the titration end-point. Benesch and Benesch (1948) applied this technique to the determination of sulphydryl groups in serum protein, and Weissman, Schoenbach, and Armistead (1950) used the same method in a study of the sulphydryl content of albumin and globulin fractions in

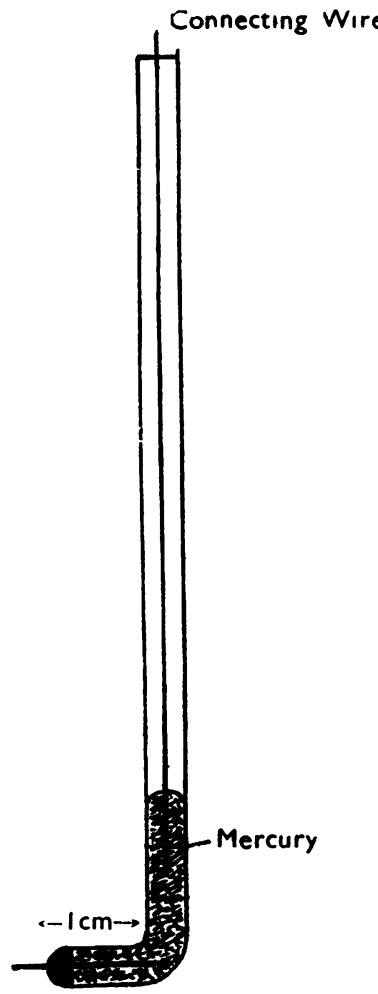

FIG. 1 normal sera.

Since variations in the sulphydryl concentration of the blood are of interest to workers in the field of rheumatic diseases and to those concerned with diabetes, it was considered that a relatively simple method of estimating blood "glutathione" might usefully be evolved from an amperometric titration procedure. This proved to be correct. A description of the apparatus, an account of the technique, and of the results obtained, are now presented.

\section{Experimental}

Apparatus.-The apparatus follows the design of Kolthoff and Harris (1946) with certain modifications, and consists essentially of a rotating electrode, a reference halfcell, a salt-bridge, a micro-ammeter or galvanometer, and a microburette.

Rotating Electrode $(A)$. - The electrode consists of about $15 \mathrm{~cm}$. of $5 \mathrm{~mm}$. bore soft-glass tubing bent at right angles at one end to give approximately $1 \mathrm{~cm}$. length in the bent section. Into the angle piece is fused a platinum wire $0.5 \mathrm{~mm}$. thick, so that $6 \mathrm{~mm}$. length of wire protrudes from the end of the tube, and the free end of the wire lies inside the glass tube. Contact is made by pouring a small quantity of mercury into the glass tube (Fig. 1). The glass electrode is fitted into a hollow shaft surmounted by a pulley running in a vertical bearing and driven by a small electric motor. The pulley wheel is attached to the shaft 
and has a central hole so that a wire can be passed through the rotating shaft into the mercury contact at the bottom of the electrode.

Reference Half-Cell $(B)$. - This is a mercury mercuric iodide cell having a potential of -0.23 volt against the saturated calomel electrode. It is set up in the type of glass container used for calomel electrodes fitted with a side-arm and stopcock. A layer of mercury serves as the electrode, and sufficient should be added to give the maximum surface area in order to prevent polarization. The remainder of the cell, including its side-arm, is filled with electrolyte, which consists of $4.2 \mathrm{~g}$. of potassium iodide and $1.3 \mathrm{~g}$. of mercuric iodide dissolved in $100 \mathrm{ml}$. of saturated potassium chloride solution.

Salt-Bridge $(C)$.-The side-arm of the half-cell dips into a beaker containing saturated potassium chloride. A piece of $6 \mathrm{~mm}$. glass tubing approximately $60 \mathrm{~cm}$. long is filled with a gel of $3 \%$ agar in saturated potassium chloride and is bent into a rough inverted U-shape, so that one end dips into the beaker of potassium chloride solution and the other into the beaker containing the solution under titration. The actual shape of the tube depends entirely upon the particular assembly in use. The agar bridge lasts for some months before renewal is necessary. Shrinkage of the agar does not interfere with the conductivity, provided that no cracks or splits occur. During use the electrolyte in the reference half-cell slowly diffuses into the beaker of saturated potassium chloride and vice versa. When this has occurred to some extent, the galvanometer response may be sluggish and weak. Renewal of the electrolyte usually remedies this. The top surface of the beaker containing saturated potassium chloride, the whole of the side-arm of the reference half-cell, and about $10 \mathrm{~cm}$. of the end of the agar-bridge dipping into the beaker should be thoroughly greased with vaseline to prevent the potassium chloride " creeping," as this may cause other electric potentials to be set up which interfere with the normal galvanometer readings.

Current Measuring Device (D).-A reliable micro-ammeter registering 0-10 microamp. in divisions of 0.2 micro-amp. has been found to give excellent results. A Cambridge spot galvanometer, $450 \mathrm{ohms}$, is also satisfactory when used with a variable shunt resistance of $5,000 \mathrm{ohms}$, although, due to the greater sensitivity of the galvanometer, the readings are not so precise as those of the micro-ammeter. In general, the lowest sensitivity consistent with accurate readings gives the best results.

The Micro-burette $(E)$.-A $1 \mathrm{ml}$. self-filling burette with three way stopcock graduated in $0.01 \mathrm{ml}$. is used, with a drawn-out tip so that one drop measures not more than 0.01 $\mathrm{ml}$. This gives a slow running time to the burette and enables $0.1 \mathrm{ml}$. aliquots to be run out accurately.

Assembly of Apparatus.-By means of a wire making contact with the mercury, the rotating electrode is connected to the positive terminal of the micro-ammeter; the reference electrode is wired to the negative terminal. The micro-burette is secured in a clamp so that the delivery tip is as close as possible to the rotating electrode without interfering with its movement. Another clamp holds the agar salt-bridge, one end of which is placed close to and approximately level with the platinum electrode, while the other end dips into the saturated potassium chloride. As described above, the side-arm of the reference half-cell also dips into the beaker of potassium chloride. The circuit is completed by the solution to be titrated, which is contained in a $150 \mathrm{ml}$. beaker held in a retort clamp so arranged that by simply raising or lowering the beaker the contents make or break the circuit between the rotating electrode and the agar bridge. Thus all other parts of the circuit are fixtures, but the $150 \mathrm{ml}$. beaker is changed for each titration (Fig. 2).

Method.-A protein-free trichloracetic acid extract of blood is titrated with silver nitrate, and the progress of the reaction of sulphydryl compounds with Ag ions followed 


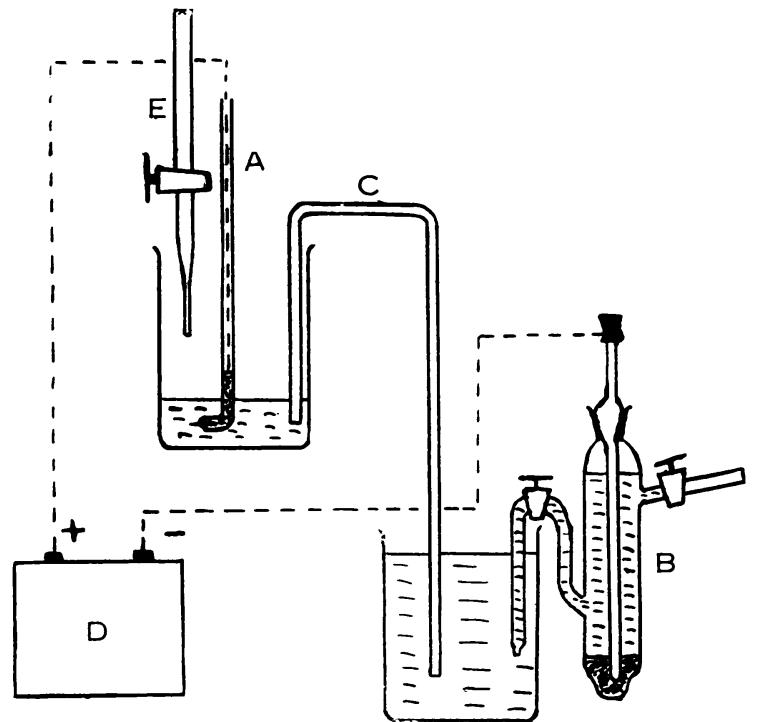

FIG. 2

amperometrically. With a suitable potential difference, silver is electro-reduced and a diffusion current flows between the two electrodes. In a supporting electrolyte of ammonia and ammonium nitrate the initial addition of silver causes precipitation of thiols as silver mercaptide (RSAg), after which further additions produce a progressively rising current proportional to the ionic concentration of silver. Chloride does not interfere with the titration. By incorporating alcohol in the reaction mixture, the decreased solubility of silver mercaptide allows a more clearcut end-point to be obtained.

Technique.-Whole blood, 1 ml., freshly drawn into an allglass syringe is laked with $3 \mathrm{ml}$. of glass-distilled water in an acid-washed centrifuge tube. After five minutes $4 \mathrm{ml}$. of $10 \%$ trichloracetic acid are added and well mixed. The tube is then centrifuged at 3,000 revs. for five minutes.

In a clean $150 \mathrm{ml}$. beaker, $21 \mathrm{ml}$. of $0.06 \mathrm{M}$ ammonium nitrate solution are mixed with $4 \mathrm{ml}$. of pure ethyl alcohol and $4 \mathrm{ml}$. of the supernatant fluid from the centrifuge tube. I he beaker is now clamped in position so that the electrode and the end of the salt-bridge are covered by the contents. The electrode is set rotating and the side-arm stopcock of the reference half-cell is opened. The micro-ammeter should register a relatively high current (6-8 micro-amp.). Whilst the electrode is rotating, two drops $(0.1 \mathrm{ml}$.) of ammonia solution (sp. gr. 0.880) are carefully added. On addition of the second drop the microammeter needle should quickly return to a minimum value. This value varies from time to time, depending upon the number of previous estimations, if any, and the state of the reference half-cell, but it is usually from 0.4-1.0 micro-amp. Immediately after adding the

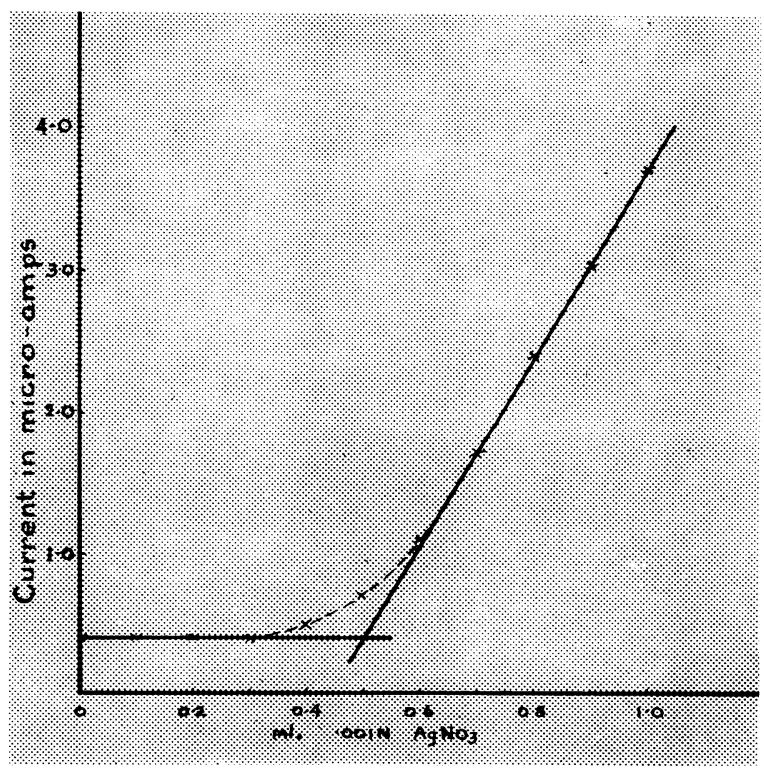

FIG. 3 
ammonia, the titration is begun : $0.001 \mathrm{~N}$ silver nitrate is run into the beaker $0.1 \mathrm{ml}$. at a time, the reading of the micro-ammeter being noted after each addition. The readings remain stationary for the first few additions of silver nitrate and near the end-point begin to increase. About six more readings are taken after the initial movement.

Duplicate titrations should be made on each test sample. Before beginning a series of determinations a blank titration of $25 \mathrm{ml}$. of ammonium nitrate solution, $4 \mathrm{ml}$. of alcohol, and $0.1 \mathrm{ml}$. of ammonia should be made to enable the apparatus to be checked for satisfactory performance. The micro-ammeter response should be almost immediate, and the blank titration will not be more than $0.05 \mathrm{ml}$. of $0.001 \mathrm{~N}$ silver nitrate.

The end-point is found graphically (Fig. 3) by plotting the diffusion current against the volume of silver nitrate. One line can be drawn through the stationary readings of the micro-ammeter and a second straight line through the increasing readings. At the point where these lines intersect the corresponding volume of silver nitrate is read, and this volume multiplied by 200 gives the number of micromoles sulphydryl per $100 \mathrm{ml}$. of blood. Conversion to glutathione ( $\mathrm{mg}$. per $100 \mathrm{ml}$.) is readily obtained by multiplying $\mu \mathrm{M}$ sulphydryl per $100 \mathrm{ml}$. by 0.307 .

General Observations.-After about 30 titrations have been carried out the platinum electrode becomes slightly coated with silver, with consequent loss of sensitivity. However, the efficiency of the electrode is easily restored by cleaning it in nitric acid when necessary.

The reaction mixture should have a $p \mathrm{H}$ of $8.5-9.0$; excess ammonia must not be added. If the titration is delayed after adding $0.1 \mathrm{ml}$. ammonia low results will be obtained. The silver nitrate solution $(0.001 \mathrm{~N})$ is best prepared freshly each day from a $0.1 \mathrm{~N}$ solution contained in a dark bottle. Industrial methylated spirit may be used in place of ethyl alcohol, provided that the spirit has not at any time been stored in metal containers. All reagents must be free from traces of iron and copper.

\section{Results}

To test the accuracy of the method, the following procedures were carried out. Eight aqueous solutions containing amounts of glutathione (GSH) unknown to the operator were titrated. The mean percentage recovery was 96 (range, 91-98\%). Volumes of glutathione solutions chosen at random and representing 10,20 , or $30 \mathrm{mg}$. GSH per $100 \mathrm{ml}$. of blood were added to laked blood samples of known sulphydryl content ; the amount of GSH then estimable was found by titration. In 40 such experiments the mean recovery of added GSH was $98.4 \%$ (S.D. $\pm 4.3 \%$ ).

Table I presents values for the glutathione content of 45 different samples of blood as determined by silver titration, by the iodometric assay of Woodward and Fry (1932), and by a recently improved nitroprusside reaction (Thompson and Watson, 1952).

The sulphydryl groups of ergothioneine hydrochloride and cysteine hydrochloride are, as expected, estimable by silver titration. Ergothioneine hydrochloride is also recoverable when added to protein-free blood filtrates. When, however, this substance is added to blood before its laking with water, ergothioneine is not titratable under our experimental conditions, and is apparently removed with the protein precipitate.

\section{Discussion}

The values given in Table I are comparative only and do not necessarily represent the true in vivo blood GSH levels. Nevertheless it will be seen that results obtained by the colorimetric nitroprusside method and by the method now advocated are in good agreement, while those obtained by the iodometric procedure are high. 
TABLE I

Comparison of Glutathione Values of 45 Whole Bloods by Three Methods

\begin{tabular}{|c|c|c|c|}
\hline Prese & nt Method & Thompson and Watson (1952) & Woodward and Fry (1932) \\
\hline & $\begin{array}{l}36 \cdot 0 * \\
35 \cdot 6 \\
42 \cdot 3 \\
32 \cdot 9 \\
27 \cdot 6 \\
41 \cdot 8 \\
30 \cdot 7 \\
30 \cdot 7 \\
40 \cdot 6 \\
33 \cdot 8 \\
31 \cdot 7 \\
33 \cdot 1 \\
32 \cdot 0 \\
31 \cdot 9 \\
35 \cdot 6 \\
44 \cdot 7 \\
34 \cdot 1 \\
36 \cdot 8 \\
33 \cdot 1 \\
35 \cdot 6 \\
31 \cdot 9 \\
35 \cdot 0 \\
35 \cdot 0 \\
29 \cdot 2 \\
28 \cdot 9 \\
27 \cdot 0 \\
27 \cdot 0 \\
32 \cdot 5 \\
28.8 \\
26.4 \\
33 \cdot 2 \\
32 \cdot 5 \\
33 \cdot 1 \\
29 \cdot 4 \\
39 \cdot 9 \\
24 \cdot 5 \\
25 \cdot 8 \\
31 \cdot 3 \\
25 \cdot 8 \\
33 \cdot 0 \\
25 \cdot 2 \\
22 \cdot 1 \\
30 \cdot 7 \\
27 \cdot 6 \\
22 \cdot 1\end{array}$ & $\begin{array}{l}39 \cdot 1 \\
34 \cdot 2 \\
38 \cdot 8 \\
31 \cdot 9 \\
25 \cdot 0 \\
42 \cdot 1 \\
32 \cdot 7 \\
34 \cdot 0 \\
44 \cdot 0 \\
37 \cdot 0 \\
39 \cdot 0 \\
35 \cdot 0 \\
36 \cdot 5 \\
30 \cdot 6 \\
29 \cdot 6 \\
42 \cdot 0 \\
30 \cdot 0 \\
32 \cdot 0 \\
27 \cdot 0 \\
29 \cdot 3 \\
26 \cdot 5 \\
32 \cdot 4 \\
36 \cdot 7 \\
28 \cdot 8 \\
32 \cdot 2 \\
27 \cdot 2 \\
27 \cdot 0 \\
34 \cdot 3 \\
31 \cdot 1 \\
26 \cdot 5 \\
33 \cdot 8 \\
32 \cdot 5 \\
32 \cdot 9 \\
29 \cdot 8 \\
38 \cdot 8 \\
26 \cdot 2 \\
29 \cdot 2 \\
33 \cdot 6 \\
30 \cdot 0 \\
36 \cdot 7 \\
28 \cdot 3 \\
22 \cdot 7 \\
30 \cdot 2 \\
27 \cdot 6 \\
22 \cdot 4\end{array}$ & $\begin{array}{l}41 \cdot 4 \\
40 \cdot 2 \\
39 \cdot 7 \\
34 \cdot 2 \\
28 \cdot 5 \\
37 \cdot 1 \\
32 \cdot 8 \\
34 \cdot 3 \\
46 \cdot 8 \\
44 \cdot 4 \\
35 \cdot 7 \\
31 \cdot 3 \\
35 \cdot 7 \\
33 \cdot 4 \\
38 \cdot 4 \\
48 \cdot 3 \\
32 \cdot 7 \\
35 \cdot 6 \\
32 \cdot 7 \\
32 \cdot 7 \\
29 \cdot 9 \\
35 \cdot 6 \\
38 \cdot 4 \\
31 \cdot 3 \\
35 \cdot 6 \\
32 \cdot 8 \\
28 \cdot 5 \\
41 \cdot 4 \\
32 \cdot 8 \\
29 \cdot 9 \\
42 \cdot 7 \\
44 \cdot 0 \\
38 \cdot 4 \\
29 \cdot 9 \\
44 \cdot 2 \\
27 \cdot 0 \\
28 \cdot 5 \\
35 \cdot 6 \\
31 \cdot 3 \\
44 \cdot 0 \\
39 \cdot 9 \\
27 \cdot 0 \\
38 \cdot 4 \\
35 \cdot 6 \\
28 \cdot 5\end{array}$ \\
\hline $\begin{array}{l}\text { Mean of } \\
\text { results } \\
\text { Standard } \\
\text { deviation }\end{array}$ & $\begin{array}{r}32 \cdot 0 \\
\pm 5 \cdot 1\end{array}$ & $\begin{array}{r}32 \cdot 2 \\
\pm 5 \cdot 1\end{array}$ & $\begin{array}{r}35 \cdot 5 \\
\pm 5 \cdot 1\end{array}$ \\
\hline
\end{tabular}

* Results expressed in mg. GSH per $100 \mathrm{ml}$.

Woodward and Fry (1932) tested their iodometric analysis for blood glutathione for possible interference by certain non-thiol reducing substances present in blood filtrates. Although they apparently did not consider the presence of ascorbic acid, 
one substance, ergothioneine, was shown to be the cause of an error to the extent of about $3 \mathrm{mg}$. per $100 \mathrm{ml}$. blood. By the present technique ergothioneine is not estimated, a fact which might account for the discrepancy between the results obtained by these two methods. While it is possible that other non-protein sulphydryl compounds, e.g. peptides of cysteine, may contribute both to a nitroprusside colour and to the formation of a silver salt, it is clear from our results that iodometric titration is a less specific determinative procedure for blood glutathione.

Since it is known that oxidized thiols do not give the nitroprusside colour reaction, the agreement shown by the nitroprusside and present procedures suggests that disulphides do not interfere with our estimation of glutathione. In view of work by Cecil (1950) on the potentiometric analysis of aqueous thiols and disulphides, a few analyses were made on a specimen of blood to some samples of which oxidized glutathione (G.S.S.G.) had been added. There was virtually no difference in the calculated glutathione content of the samples. Hydrolytic decomposition of oxidized glutathione does not therefore occur during the titration of glutathione.

\section{Summary}

A simple and rapid technique is described for the determination of blood glutathione.

Results are given for recoveries of glutathione added to blood of known sulphydryl content, and for the estimation of blood non-protein sulphydryl compounds carried out in parallel by iodometric and nitroprusside methods, and by a silver nitrate titration.

Titration with $\mathrm{Ag}$ ions to an amperometrically found end-point is shown to provide a more accurate, specific, and reliable method for the determination of reduced glutathione in blood.

The authors wish to thank Dr. G. D. Kersley, director of the Rheumatism Research Unit, for a helpful discussion on this work, and are also grateful to Dr. H. J. Gibson, Royal National Hospital for Rheumatic Diseases, Bath, for the provision of many of the blood samples.

We are indebted to Messrs. Burroughs Wellcome and Co. for a gift of ergothioneine.

REFERENCES

Benesch, R., and Benesch, R. E. (1948). Arch. Biochem., 19, 35.

Cecil, R. (1950). Biochem. J., 47, 572.

Kolthoff, I. M., and Harris, W. E. (1946). Industr. Engng. Chem. (Anal. ed.), 18, 161.

Thompson, R. H. S., and Watson, D. (1952). Journal of Clinical Pathology, 5, 25.

Weissman, N., Schoenbach, E. B., and Armistead, E. B. (1950). J. biol. Chem., 187, 153.

Woodward, G. E., and Fry, E. G. (1932). Ibid., 97, 465. 